\title{
Coagulation factors and COVID-19 severity: Mendelian randomization analyses and supporting evidence
}

Yao Zhou ${ }^{1,2}$, Zipeng Liu ${ }^{3}$, Hongxi Yang ${ }^{2,4}$, Jianhua Wang ${ }^{1,2}$, Tong Liu ${ }^{5}$, Kexin Chen ${ }^{6}$, Yaogang Wang ${ }^{4}$, Pak Chung Sham ${ }^{3}$, Ying $\mathrm{Yu}^{2}$, Mulin Jun Li ${ }^{1,2,6, *}$

${ }^{1}$ The Province and Ministry Co-sponsored Collaborative Innovation Center for Medical Epigenetics, Tianjin Medical University Cancer Institute and Hospital, Tianjin Medical University, Tianjin, China.

${ }^{2}$ Department of Pharmacology, Tianjin Key Laboratory of Inflammation Biology, School of Basic Medical Sciences, Tianjin Medical University, Tianjin, China.

${ }^{3}$ Centre for PanorOmic Sciences-Genomics and Bioinformatics Cores, The University of Hong Kong, Hong Kong.

${ }^{4}$ Department of Health Service Management, School of Public Health, Tianjin Medical University, Tianjin, China.

${ }^{5}$ Department of Cardiology, Tianjin Key Laboratory of Ionic-Molecular Function of Cardiovascular Disease, Tianjin Institute of Cardiology, Second Hospital of Tianjin Medical University, Tianjin, China.

${ }^{6}$ Department of Epidemiology and Biostatistics, National Clinical Research Center for Cancer, Key Laboratory of Molecular Cancer Epidemiology of Tianjin, Tianjin Medical University Cancer Institute and Hospital, Tianjin Medical University, Tianjin, China.

*Correspondence should be addressed to Mulin Jun Li (e-mail: mulinli@ connect.hku.hk)

\section{Abstract}

\section{Background:}

The evolving pandemic of COVID-19 is arousing alarm to public health. According to epidemiological and observational studies, coagulopathy was frequently seen in severe COVID-19 patients, yet the causality from specific coagulation factors to COVID-19 severity and the underlying mechanism remain elusive.

\section{Methods:}

First, we leveraged Mendelian randomization (MR) analyses to assess causal relationship between 12 coagulation factors and severe COVID-19 illness based on two genome-wide association study (GWAS) results of COVID-19 severity. Second, we curated clinical evidence supporting causal associations between COVID-19 severity and particular coagulation factors which showed significant results in MR analyses. Third, we validated our results in an independent cohort from UK Biobank (UKBB) using polygenic risk score (PRS) analysis and logistic regression model. For all MR analyses, GWAS summary-level data were used to ascertain genetic effects on exposures against disease risk.

\section{Results:}

We revealed that genetic predisposition to the antigen levels of von Willebrand factor (VWF) and the activity levels of its cleaving protease ADAMTS13 were causally associated with COVID-19 severity, wherein elevated VWF antigen level $(P=0.005$, odds ratio $(\mathrm{OR})=1.35,95 \%$ confidence interval $(\mathrm{CI}): 1.09-1.68$ in the Severe 
COVID-19 GWAS Group cohort; $P=0.039$, OR $=1.21,95 \%$ CI: $1.01-1.46$ in the COVID-19 Host Genetics Initiative cohort) and lowered ADAMTS13 activity $(P=$ 0.025, OR $=0.69,95 \%$ CI: 0.50-0.96 in the Severe COVID-19 GWAS Group cohort) lead to increased risk of severe COVID-19 illness. No significant causal association of tPA, PAI-1, D-dimer, FVII, PT, FVIII, FXI, aPTT, FX or ETP with COVID-19 severity was observed. In addition, as an independent factor, VWF PRS explains a $31 \%$ higher risk of severe COVID-19 illness in the UKBB cohort $(P=0.047$, OR per SD increase $=1.31,95 \%$ CI: 1.00-1.71). In combination with age, sex, BMI and several pre-existing disease statues, our model can predict severity risks with an AUC of 0.70 .

\section{Conclusion:}

Together with the supporting evidence of recent retrospective cohort studies and independent validation based on UKBB data, our results suggest that the associations between coagulation factors VWF/ADAMTS13 and COVID-19 severity are essentially causal, which illuminates one of possible mechanisms underlying COVID19 severity. This study also highlights the importance of dynamically monitoring the plasma levels of VWF/ADAMTS13 after SARS-CoV-2 infection, and facilitates the development of treatment strategy for controlling COVID-19 severity and associated thrombotic complication.

\section{Introduction}

The outbreak of coronavirus disease 19 (COVID-19), which is caused by severe acute respiratory syndrome coronavirus 2 (SARS-CoV-2), with an unprecedented number of pneumonia cases from the late December 2019 put people on full alert ${ }^{1}$. Widespread comorbidities implicating several organs were frequently observed in COVID-19 patients, such as diseases in cardiovascular, neurological and hematopoietic systems ${ }^{2}$. Of note, COVID-19-associated coagulopathy is a common complication among those patients developing severe systemic diseases and multiorgan failure ${ }^{3-5}$, suggesting the importance of exploring clinical markers and the causal association between coagulopathy and COVID-19 ${ }^{6}$.

Some coagulation parameters including D-dimer, prothrombin time (PT), von Willebrand factor (VWF), platelet count, and fibrinogen were previously documented to be important predictors of critically ill patients with COVID-19 ${ }^{7-9}$. A recent study revealed that specific coagulation biomarkers, such as VWF and factor VIII (FVIII) levels, are independent predictors of increased oxygen requirements in COVID $\square 19$ patients ${ }^{10}$. It has also been observed that hospitalized COVID-19 patients, especially those with severe respiratory or systemic symptoms, are at increased risk for thromboembolism ${ }^{11,12}$ and aberrant bleeding manifestations ${ }^{13,14}$. Moreover, alveolar capillary microthrombi were 9 times as prevalent in patients who died from COVID19 as those who died from H1N1 influenza ${ }^{15}$. These retrospective observational studies clearly demonstrated the remarkable relevance among coagulation factor levels, thrombotic complications and COVID-19 severity. Nevertheless, it remains unclear which coagulation factor(s) can faithfully indicate the severity of COVID-19 illness or whether genetic predisposition to coagulation factor levels is causally related to severity and mortality of COVID-19 as well as the underlying biological 
pathways.

In the present study, by comprehensively integrating GWAS results of coagulation factors from different resources, we first utilized Mendelian Randomization (MR) analyses to investigate the causal relationships between coagulation factors and COVID-19 severity. We revealed that the antigen levels of VWF and the activities of its cleaving protease, a disintegrin and metalloproteinase with a thrombospondin type 1 motif, member 13 (ADAMTS13), causally modulate the development of severe COVID-19. Furthermore, we found polygenic risk score (PRS) of VWF is an independent clinical risk factor for predicting COVID-19 severity using UKBB COVID-19 data.

\section{Methods}

\section{Data sources}

\section{Instrumental variables for coagulation factors}

As summarized in Supplementary Table 1, we searched PubMed and GWAS Catalog

16 for the coagulation factor-relevant GWASs in European ethnic participants to identify genetic variants that could be used as instrumental variables for two-sample MR analysis. We selected single-nucleotide polymorphisms (SNPs) at genome-wide significant level $(P<5 \mathrm{E}-8)$, while findings showing modest significance $(P<5 \mathrm{E}-7)$ were also incorporated. The identified coagulation factors with genetic instruments include (1) Factor VIII (FVIII), Factor XI (FXI) and activated partial thromboplastin time (aPTT) that involved in intrinsic pathways; (2) Factor X (FX) and endogenous thrombin potential (ETP) that involved in common pathways; (3) Factor VII (FVII) and prothrombin time (PT) that involved in extrinsic pathways; (4) VWF and ADAMTS13 that involved in platelet adhesion; (5) D-dimer, tissue plasminogen activator (tPA), and plasminogen activator inhibitor-1 (PAI-1) concentration that involved in the dissolution of fibrin clot. Only coagulation factors with more than 3 genetic instruments were included in this study.

\section{GWAS summary statistics for severe COVID-19}

GWAS summary statistics for severe COVID-19 with respiratory failure were obtained from two sources, (1) the GWAS of severe COVID-19 with respiratory failure from the Severe COVID-19 GWAS Group (http://www.c19-genetics.eu), which was based on 1,610 patients and 2,205 control participants in European ethnic groups, wherein age, sex, and top 10 genetic components were adjusted ${ }^{17}$; (2) the GWAS of COVID-19 with very severe respiratory confirmed from the COVID-19 Host Genetics Initiative (https://www.covid19hg.org, round 4, A2_ALL), which was based on 2,972 patients and 284,472 control participants in mixed ethnic groups (mainly from European population) ${ }^{18}$.

\section{UKBB COVID-19 data}

The COVID-19 inspections result from the UKBB (up to 2020/10/7) was used, which included 1621 unrelated (kinship coefficient $>0.0884$, corresponding to 3rd-degree relationships) UKBB participants of European ancestry (mean age 69.2 years; 53.2\% men). All these participants were laboratory-confirmed COVID-19 patients. Baseline 
demographic and clinical characteristics of these participants are summarized in Supplementary Table 2 .

The information of COVID-19 diagnosis was obtained from COVID-19 test results provided by Public Health England (PHE); death register provided by the National Health Service (NHS) Digital and NHS Central Register (NHSCR); hospital inpatient data provided by NHS Digital; and primary care data provided by TPP systems (https://www.tpp-uk.com/) and EMIS (https://www.emishealth.com/) systems. The selection criteria of UKBB participants included: ever reported as positive for SARSCoV-2 by PHE; death from COVID-19 as the underlying cause (International Classification of Diseases, Tenth Revision (ICD-10): U071); hospitalization for COVID-19 (ICD-10: U071) from Hospital Episode Statistics; or confirmed COVID19 infection from primary care data (Clinical Terms Version 3 (CTV3): Y20d1, EMIS: EMISNQCO303 or SNOMED CT: 1240581000000100).

Individual genotypes that primarily called by two genotyping arrays known as UKBB Axiom array and UK BiLEVE Axiom array were imputed to 92 million autosomal and X-chromosome variants using merged panel comprised of UK10K haplotype reference panel and 1000 Genomes Phase 3 reference panel by UKBB.

\section{Mendelian randomization}

\section{Instruments construction}

The MR framework used in this study was shown in Supplementary Fig. 1. To ensure valid instruments selection according to MR analysis criteria 19, 20, we first harmonized instrumental SNPs for each exposure GWAS by (1) excluding SNPs associated with other potential confounders (body mass index, lipid and metabolic diseases, etc.) of exposure-outcome associations by searching PhenoScanner ${ }^{21}$; (2) excluding SNPs located in the major histocompatibility complex (MHC) human leukocyte antigen (HLA) region from the list of instrumental SNPs due to potential horizontal pleiotropy with other confounder traits such as metabolic diseases and immune diseases ${ }^{22-24}$; (3) excluding rare SNPs (minor allele frequency < 0.01) from the list of instrumental SNPs; (4) standardizing the effect size $(\beta)$ and standard error (SE) for each SNP by the following formula ${ }^{25}$ :

$$
\beta=\frac{z}{\sqrt{2 f(1-f)\left(n+z^{2}\right)}}, \mathrm{SE}=\frac{1}{\sqrt{2 f(1-f)\left(n+z^{2}\right)}}
$$

where $z=\beta /$ SE from the original summary data, $f$ is the effect allele frequency, and $n$ is the total sample size.

For SNPs that were not available in the GWAS data of COVID-19 severity, we used the LDlink tool ${ }^{26}$ to find the most correlated proxies ( $\mathrm{r} 2>0.8$ ), and the summarylevel statistics for proxy SNPs were used instead. Based on SNPs reported to be associated with certain exposure by the above GWAS studies, we further applied the linkage disequilibrium (LD)-based clumping implemented in PLINK ${ }^{27}\left(\mathrm{r}^{2}\right.$ threshold $=$ 0.01 and window size $=10 \mathrm{Mb}$ ) to ensure the independence of selected SNPs. Individual-level genotype data from European population of 1000 Genomes project 
served as the reference panel in this study. The final SNPs used as instruments in this study are summarized in Supplementary Table 3.

\section{MR statistical analysis}

Several MR methodologies including Inverse variance weighted (IVW), MR-Egger regression, and weighted median (WM) methods were used to estimate the causal effects, wherein IVW was used in the main analysis ${ }^{28,29}$. We obtained Wald ratio estimates for each instrumental SNP on COVID-19 severity, and then combined Wald ratio estimates using inverse variance weighting with fixed effects. To identify potential horizontal pleiotropy, we searched PhenoScanner ${ }^{21}$ to explore whether instrumental SNPs are associated with other potential cofounders of exposureoutcome associations. Moreover, we further performed several sensitivity analyses to assess the robustness of our findings by (1) we evaluated heterogeneity for causal estimates that calculated by MR-Egger regression and IVW among instrument SNPs based on Cochran's Q statistic ${ }^{30}$ and then used Mendelian Randomization Pleiotropy RESidual Sum and Outlier (MR-PRESSO) global test ${ }^{31}$ to detect global pleiotropy; (2) when the global test was significant $(P<0.05)$, we removed statistically significant outliers detected by MR-PRESSO outlier test $(P<0.05)$ and repeated MR analysis; $(3)$ to avoid multiple comparisons problem, we applied Benjamini-Hochberg method to control False discovery rate (FDR significance threshold $=0.1)$, and the BH-adjusted $P$-values of IVW method were used in multiple comparisons correction. IVW, MREgger regression, WM methods were implemented in $\mathrm{R}$ package TwoSampleMR v0.5.4; MR-PRESSO global test and outlier test were implemented in R package MRPRESSO.

\section{Evaluation based on UKBB COVID-19 data}

Severe COVID-19 cases from the UKBB cohort were defined as laboratory- or clinical- diagnosed COVID-19 patients with at least one of the following clinical features: (1) receiving care in the intensive care unit (ICU); (2) hospitalized inpatients; (3) depending on invasive ventilation using ventilator or ventilatory supports; (4) depending on noninvasive ventilation using other enabling machines and devices. We used PRSice- $2^{32}$ to construct the PRS of VWF based on the effect sizes derived from the VWF GWASs and then investigated its association with the risk of critical illness in the COVID-19 patients from UKBB cohort. PRS based on significant instrumental SNPs of VWF were calculated by the following formula ${ }^{32}$ :

$$
\mathrm{PRS}_{j}=\sum_{i} \beta_{i} \mathrm{~g}_{i j}
$$

Where $j$ indicates $j^{\text {th }}$ individual and $i$ indicates $i^{\text {th }}$ variant, $\mathrm{g}$ is the number of risk alleles carried ( $g \in\{0,1,2\}), \beta$ is the harmonized effect size derived from the VWF GWASs.

We applied a multivariable logistic regression model to determine the association between the VWF PRS and COVID-19 severity risk with adjustments for age, sex, 
body mass index (BMI), systolic blood pressure (SBP), top 10 principal components of genetic variations, history of coronary artery disease (CAD), type 2 diabetes mellitus (T2DM), and chronic obstructive pulmonary disease (COPD). The significance of regression coefficients was determined by Wald statistics test under null hypothesis that the variable has no correlation with COVID-19 severity risk. To demonstrate the predictive power of PRS, we trained two logistic regression models with (1) clinical risk factors and (2) clinical risk factors + VWF PRS. Before fitting the models, we applied z-score normalization to transform raw values of variables into a same scale. We used 10-fold cross-validation in the fitting process. Specifically, we randomly divided the entire sample into 10 equal-sized sub-samples, then iteratively fitted the model using the nine folds and validated the model using the remaining one fold. Furthermore, to evaluate the fit of the model, we took the mean value of an area under the receiver operating characteristic curve (AUC) measurement among the 10 iterations.

\section{Results}

\section{Causal effect of coagulation factor levels on COVID-19 severity}

We systematically curated genome-wide significant SNPs associated with 12 coagulation factors from 15 GWASs, including VWF, ADAMTS13, tPA, PAI-1, Ddimer, FVII, PT, FVIII, FXI, aPTT, FX and ETP (Supplementary Table 2). The number of instrumental SNPs for each coagulation factor was summarized in Table 1. After correlated instruments removal and effect size harmonization, we performed IVW MR to test the causal effect of each coagulation factor on COVID-19 severity (Fig. 1). As summarized in Table 1, MR results based on two existing COVID-19 severity GWAS datasets showed consistent directions and comparable magnitudes of effect size. According to COVID-19 GWAS result from the Severe COVID-19 GWAS Group ${ }^{17}$, among all investigated coagulation factors, we observed that VWF $\left(P_{\mathrm{IVW}}=0.005\right)$ and ADAMTS13, also known as VWF-cleaving protease $\left(P_{\mathrm{IVW}}=\right.$ $0.025)$, both showed significant results but displayed opposite direction of causal effect on COVID-19 severity (Table 1). Specifically, genetically determined plasma VWF antigen level was positively associated with the risk of severe COVID-19 ( $P_{\text {IVw }}$ $=0.005$, odds ratio $(\mathrm{OR})=1.35,95 \%$ confidence interval $(\mathrm{CI}): 1.09-1.68)$ based on 17 instrumental SNPs (Supplementary Fig. 2). The significance remains after multiple testing correction (FDR $=0.06$ ). After removing the instruments that are significantly associated with confounder traits, no additional pleiotropy was detected between VWF levels and COVID-19 severity by PRESSO global test $(P=0.074), \mathrm{Q}_{\text {Egger }}(P=$ $0.777)$ and $\mathrm{Q}_{\mathrm{IVM}}(P=0.515)$. IVW MR revealed that plasma ADAMTS13 activity was inversely associated with the of severe COVID-19 $\left(P_{\mathrm{IVW}}=0.025, \mathrm{OR}=0.69,95 \%\right.$ CI: 0.50-0.96) based on four instrumental SNPs (Supplementary Fig. 2), and no pleiotropy was detected by PRESSO global test $(P=0.772)$, $\mathrm{Q}_{\text {Egger }}(P=0.433)$ or $\mathrm{Q}_{\text {IVM }}(P=0.630)$. Interestingly, Given the VWF-cleaving function of ADAMTS13, this finding further supports the causal relationship between VWF levels and COVID19 severity. However, the statistical significance disappeared after multiple testing correction (FDR $=0.15)$, which might be attributed to the relatively small number of valid instrumental variables. 
In addition, based on COVID-19 severity GWAS data from the COVID-19 Host Genetics Initiative round $4^{18}$, we observed that VWF is the only coagulation factor that exhibited genetic causal associations with COVID-19 severity $\left(P_{\mathrm{WM}}=0.039\right.$, Table 1), even though there was no other MR methods to support the association except MR WM method. MR WM identified that VWF antigen level was positively associated with the risk of severe COVID-19 $\left(P_{\mathrm{WM}}=0.039, \mathrm{OR}=1.21,95 \% \mathrm{CI}\right.$ : 1.01-1.46). Sensitivity analyses supported the robustness of the result, where no pleiotropy was detected by PRESSO global test $(P=0.718)$, Q $\mathrm{Qgger}_{(}(P=0.623)$ and QIvM $(P=0.680)$. However, no significant signal was observed from the results of ADAMTS13 MR analyses (Supplementary Fig. 2). Taken together, these results confirmed that elevated VWF is a potential causal factor for COVID-19 severity.

\section{The supporting evidence of VWF-ADAMTS13 as biomarkers for COVID-19 severity}

A growing body of studies reported that hypercoagulation status was frequently seen in COVID-19 patients ${ }^{33,34}$. We also performed literature review to summarize existing clinical epidemiological studies regarding VWF/ADAMTS13 and COVID-19 severity. Majority of curated studies showed that the elevation of VWF antigen levels and the reduced ADAMTS13 activities are associated with COVID-19 severity (Table 2). Besides, a multi-omics analysis leveraged RNA-Seq and high-resolution mass spectrometry on 128 blood samples from COVID-19 positive and negative patients with diverse disease severities, and found VWF antigen level is significantly higher in COVID-19 patients when compared to normal controls ${ }^{35}$. We also confirmed that the VWF protein level is significantly higher in ICU COVID-19 patients compared to non-ICU patients based on their released peptide quantifications (Supplementary Fig. 3). These evidences largely support that the antigen level of blood-derived VWF is an associated biomarker for COVID-19 severity.

\section{PRS analyses on UKBB COVID-19 cohort}

According to the released COVID-19 inspection results from UKBB (up to 2020/10/7), 1,621 samples with European ethnic background were laboratory- or clinical- diagnosed as COVID-19 positive individuals. Among these positive individuals, 693 patients are classified as severe cases and remaining individuals are used as controls based on their clinical manifestations (see Methods for details). Using this independent UKBB cohort for COVID-19 severity (693 cases and 928 controls), we explored the predictive ability of PRS that derived from the VWFassociated genetic variants (17 instrumental SNPs) in the prediction of severe COVID-19 risk. Association of the VWF PRS and COVID-19 severity risk was determined using logistic regression model adjusted for age, sex, BMI, SBP, top 10 principal components of genetic variations, history of CAD, T2DM, and COPD (see Methods for details). Independent of clinical risk factors, VWF PRS was significantly associated with increased risk of severe COVID-19 $(P=0.047$, OR per SD increase $=$ $1.31,95 \%$ CI: $1.00-1.71)$.

Previous observational studies revealed that age, sex, BMI are critical factors for predicting severe COVID-19, in addition, disease comorbidities, such as hypertension, 
CAD, COPD and T2DM, are also important risk factors ${ }^{2,36-40}$. To investigate whether introduction of the VWF PRS could improve the prediction performance of COVID19 severity, we compared two logistic regression models with or without the VWF PRS by 10 -fold cross validation. We found that, when the VWF PRS was added to the model, the AUC for COVID-19 severity prediction was moderately increased by $0.1 \%$, wherein the first model using only clinical risk factors had a mean AUC of $0.699( \pm 0.04)$ and the second model combining clinical risk factors and the VWF PRS received a mean AUC of $0.700( \pm 0.04)$ (Fig. 2A). Since we fitted the model with z-score normalized values, the coefficients of each contributing variable can be compared directly. We observed that age is the most important risk factor for COVID19 severity, and male sex, high BMI, and history of COPD, CAD and T2DM are also effective predictors (Fig. 2B), which is consistent with previous findings ${ }^{41-43}$. Notably, VWF PRS showed larger normalized effect size than SBP (Fig. 2B), emphasizing its predictive value during the prevention and personalized treatment of COVID-19.

\section{Discussion}

Emerging evidence from observational studies showed that COVID-19 patients are prone to developing thrombotic diseases ${ }^{44,45}$ which are significantly associated with COVID-19 severity, poor prognosis and mortality risk 46, 47 . However, whether exceptional plasma levels or activities of specific coagulation factors account for a higher risk of COVID-19 severity and aberrant thrombotic manifestation is elusive. In this study, we first explored the causal relationship between multiple coagulation factors and COVID-19 severity using MR approaches. Together with the supporting evidence of recent retrospective cohort studies, our results revealed that the associations between VWF/ADAMTS13 and COVID-19 severity are essentially causal, suggesting the elevated VWF antigen and decreased ADAMTS13 activity are confident biomarkers that indicate progressive severity of COVID-19 and more aggressive critical care needed. In addition, genetic determents explain a considerable portion of the observed variance of plasma coagulation factor levels, including VWF levels ${ }^{48}$. By PRS analysis on UKBB COVID-19 cohort, we uncovered that VWF PRS is an independent contributor for COVID-19 severity prediction. When combination with age, sex, BMI and several pre-existing disease statuses, the model achieved good predictive ability in distinguishing severe cases from controls.

VWF, stored in Weibel-Palade bodies and platelet $\alpha$-granules for secretion upon stimulation, is a large multimeric glycoprotein which plays an important role in platelet recruitment after injury by forming a bridge between platelet surface receptors and endothelium ${ }^{49}$. While, ADAMTS13 is a plasma protein cleaving VWF and decreasing its activity that anchored on the endothelial surface and in circulation ${ }^{50}$. The dysfunction of VWF/ADAMTS13 dynamic equilibrium had been reported to be associated with thrombotic diseases ${ }^{51-54}$ and cardiovascular diseases ${ }^{55}$. COVID-19 patients are prone to developing thrombotic diseases 44,45 , reciprocally, the development of thrombotic diseases could account for poor prognosis and mortality of COVID-19 ${ }^{46,47}$. We suspected that SARS-COV-2 invades human lungs and causes injury or inflammation in the blood vessels, which then promoting a pro-coagulative 
state. As an important consideration for COVID-19, elevated VWF level and insufficient ADAMTS13 activity confer a higher risk of forming blood clots and ultimately develop venous thromboembolism. Thrombus can block normal blood flow and decrease oxygen supplement to alveoli, and this may explain partially why COVID-19 patients are at risk of respiratory failure. According to our MR causal inference and PRS analysis in the UKBB COVID-19 cohort, we could advise individuals carry certain VWF/ADAMTS13 alleles to closely monitor their coagulation parameters and take supportive care for coagulopathy prevention after SARS-CoV-2 infection. Also, existing drugs targeting VWF or its molecular interactions could be considered to control COVID-19 severity and associated thrombotic complication for specific cohort. Several other coagulation factors such as D-dimer and PT were previously documented to be associated with COVID-19 severity in observational studies ${ }^{7,8}$, however, we found no causal relationships through MR analyses. This phenomenon could be attributed to potential confounding factors in observational studies, where associations between coagulation factors and COVID-19 severity was not due to direct causality, but rather because both coagulation factors and COVID-19 severity are likely caused by other unrevealed confounders.

$A B O$ gene loci obtained the most prominent GWAS signal in plasma VWF levels ${ }^{48}$ and strong associations with COVID-19 ${ }^{17}$, implying ABO blood group may confound the establishment of causality between VWF/ADAMTS13 and COVID-19 severity. Recent epidemiological studies have investigated and observed tight association of ABO blood group with the COVID-19 susceptibility, severity and mortality ${ }^{56-59}$. It was also reported that the $A B O$ genotypes and $\mathrm{ABO}$ blood group are associated with ACE activity in hypertensive patients ${ }^{60}$, and increased plasma $\mathrm{ABO}$ protein is causally associated with the risk of severe COVID-19 ${ }^{61}$. Among the associated variants of VWF levels within the $A B O$ locus, SNPs rs10901252 and rs687621 can perfectly discriminate $\mathrm{B}$ and $\mathrm{O}$ blood groups from $\mathrm{A}{ }^{62}$. Individuals with blood group $\mathrm{O}$ have lower VWF plasma concentrations compared with individuals with blood group non-O ${ }^{63}$. The presence of blood group A and B antigens on VWF molecules may have clinically significant effects on VWF proteolysis and clearance ${ }^{64}$. In our analysis, we excluded SNP rs687621 due to potential horizontal pleiotropy with other traits (such as Interleukin 6 levels and coronary artery disease) and rs 10901252 for high LD with other instrumental SNPs (such as rs8176743). We found that the causality between VWF levels and COVID-19 severity was established when taking away the genetic effect of these SNPs. However, whether the causal mechanisms of VWF levels on COVID-19 severity could be independent of ABO blood group still needs further investigation.

Our study is also subject to some data limitations. First, only genome-wide significant variants were available from existing GWAS results of VWF/ADAMTS13 and most of investigated coagulator factors, which makes it impossible to perform bidirectional MR analysis, and such limited number of instrumental SNPs for particular coagulation factors could affect the accuracy of both MR and PRS estimations. Similar to recent PRS studies on $\mathrm{CAD}^{65}$ and ischemic stroke ${ }^{66}$, we observed that 
incorporation of genetic component significantly contributes the prediction model but only slightly improves the overall performance. The significant association between VWF PRS and COVID-19 severity indicated that the information captured by VWF PRS is not fully explained by other risk factors. But the current PRS study on COVID-19 cohort is likely underpowered due to insufficient sample size, the borderline significance required a larger study to ascertain the accuracy. Second, genetic risk loci for coagulation factors may vary among different populations ${ }^{67,68}$, but our study mainly focuses people from European descent. Whether there are population-specific causal mechanisms needs further exploration. Also, we didn't investigate gender- or age-specific effects because of the lack of gender- or agestratified GWAS data. Last, the sample size of severe COVID-19 GWAS is still insufficient in current stage, and further research is warranted when abundant and non-European ethnic GWAS data is available in the future. We also expect that prospective controlled trial could be applied to ascertain the causal role of VWF/ADAMTS13 and investigate potential treatments for certain infected populations.

\section{Acknowledgements}

Part of the data used in the analyses described in this manuscript were obtained from the UKBB and public GWAS resources. We appreciate all resource and tool providers.

\section{Funding}

This work was supported by grants from the National Natural Science Foundation of China 32070675, 31871327 (M.J.L.), Natural Science Foundation of Tianjin 19JCJQJC63600 (M.J.L.).

\section{Competing interests}

The authors declare that they have no competing interests.

\section{Reference}

1. Zhu N, Zhang D, Wang W, Li X, Yang B, Song J, Zhao X, Huang B, Shi W, Lu R, Niu P, Zhan F, Ma X, Wang D, Xu W, Wu G, Gao GF, Tan W, China Novel Coronavirus I and Research T. A Novel Coronavirus from Patients with Pneumonia in China, 2019. N Engl J Med. 2020;382:727-733.

2. Richardson S, Hirsch JS, Narasimhan M, Crawford JM, McGinn T, Davidson KW, the Northwell C-RC, Barnaby DP, Becker LB, Chelico JD, Cohen SL, Cookingham J, Coppa K, Diefenbach MA, Dominello AJ, Duer-Hefele J, Falzon L, Gitlin J, Hajizadeh N, Harvin TG, Hirschwerk DA, Kim EJ, Kozel ZM, Marrast LM, Mogavero JN, Osorio GA, Qiu M and Zanos TP. Presenting Characteristics, 
Comorbidities, and Outcomes Among 5700 Patients Hospitalized With COVID-19 in the New York City Area. JAMA. 2020;323:2052-2059.

3. Zhou F, Yu T, Du R, Fan G, Liu Y, Liu Z, Xiang J, Wang Y, Song B, Gu X, Guan L, Wei Y, Li H, Wu X, Xu J, Tu S, Zhang Y, Chen H and Cao B. Clinical course and risk factors for mortality of adult inpatients with COVID-19 in Wuhan, China: a retrospective cohort study. Lancet. 2020;395:1054-1062.

4. Becker RC. COVID-19 update: Covid-19-associated coagulopathy. J Thromb Thrombolysis. 2020;50:54-67.

5. Ortega-Paz L, Capodanno D, Montalescot G and Angiolillo DJ. COVID-19 Associated Thrombosis and Coagulopathy: Review of the Pathophysiology and Implications for Antithrombotic Management. J Am Heart Assoc. 2020;0:e019650.

6. The Lancet H. COVID-19 coagulopathy: an evolving story. Lancet Haematol. 2020;7:e425.

7. Liao D, Zhou F, Luo L, Xu M, Wang H, Xia J, Gao Y, Cai L, Wang Z, Yin P, Wang Y, Tang L, Deng J, Mei H and Hu Y. Haematological characteristics and risk factors in the classification and prognosis evaluation of COVID-19: a retrospective cohort study. Lancet Haematol. 2020;7:e671-e678.

8. Tang N, Li D, Wang $X$ and Sun $Z$. Abnormal coagulation parameters are associated with poor prognosis in patients with novel coronavirus pneumonia. $J$ Thromb Haemost. 2020;18:844-847.

9. Goshua $\mathrm{G}$, Pine $\mathrm{AB}$, Meizlish $\mathrm{ML}$, Chang $\mathrm{CH}$, Zhang $\mathrm{H}$, Bahel P, Baluha A, Bar N, Bona RD, Burns AJ, Dela Cruz CS, Dumont A, Halene S, Hwa J, Koff J, Menninger H, Neparidze N, Price C, Siner JM, Tormey C, Rinder HM, Chun HJ and Lee Al. Endotheliopathy in COVID-19-associated coagulopathy: evidence from a single-centre, cross-sectional study. Lancet Haematol. 2020;7:e575-e582.

10. Rauch A, Labreuche J, Lassalle F, Goutay J, Caplan M, Charbonnier L, Rohn A, Jeanpierre E, Dupont A, Duhamel A, Faure K, Lambert M, Kipnis E, Garrigue D, Lenting PJ, Poissy $\mathrm{J}$ and Susen S. Coagulation biomarkers are independent predictors of increased oxygen requirements in COVID-19. Journal of Thrombosis and Haemostasis. 2020;18:2942-2953.

11. Giannis D, Ziogas IA and Gianni P. Coagulation disorders in coronavirus infected patients: COVID-19, SARS-CoV-1, MERS-CoV and lessons from the past. $J$ Clin Virol. 2020;127:104362.

12. Connors JM and Levy JH. COVID-19 and its implications for thrombosis and anticoagulation. Blood. 2020;135:2033-2040.

13. Chan NC and Weitz JI. COVID-19 coagulopathy, thrombosis, and bleeding. 
Blood. 2020;136:381-383.

14. Al-Samkari H, Karp Leaf RS, Dzik WH, Carlson JCT, Fogerty AE, Waheed A, Goodarzi K, Bendapudi PK, Bornikova L, Gupta S, Leaf DE, Kuter DJ and Rosovsky RP. COVID-19 and coagulation: bleeding and thrombotic manifestations of SARSCoV-2 infection. Blood. 2020;136:489-500.

15. Ackermann M, Verleden SE, Kuehnel M, Haverich A, Welte T, Laenger F, Vanstapel A, Werlein C, Stark H, Tzankov A, Li WW, Li VW, Mentzer SJ and Jonigk D. Pulmonary Vascular Endothelialitis, Thrombosis, and Angiogenesis in Covid-19. N Engl J Med. 2020;383:120-128.

16. Buniello A, MacArthur JAL, Cerezo M, Harris LW, Hayhurst J, Malangone $C$, McMahon A, Morales J, Mountjoy E, Sollis E, Suveges D, Vrousgou O, Whetzel PL, Amode R, Guillen JA, Riat HS, Trevanion SJ, Hall P, Junkins H, Flicek P, Burdett T, Hindorff LA, Cunningham $\mathrm{F}$ and Parkinson $\mathrm{H}$. The NHGRI-EBI GWAS Catalog of published genome-wide association studies, targeted arrays and summary statistics 2019. Nucleic acids research. 2019;47:D1005-D1012.

17. Severe Covid GG, Ellinghaus D, Degenhardt F, Bujanda L, Buti M, Albillos A, Invernizzi P, Fernandez J, Prati D, Baselli G, Asselta R, Grimsrud MM, Milani C, Aziz F, Kassens J, May S, Wendorff M, Wienbrandt L, Uellendahl-Werth F, Zheng T, Yi X, de Pablo R, Chercoles AG, Palom A, Garcia-Fernandez AE, Rodriguez-Frias F, Zanella A, Bandera A, Protti A, Aghemo A, Lleo A, Biondi A, Caballero-Garralda A, Gori A, Tanck A, Carreras Nolla A, Latiano A, Fracanzani AL, Peschuck A, Julia A, Pesenti A, Voza A, Jimenez D, Mateos B, Nafria Jimenez B, Quereda C, Paccapelo C, Gassner C, Angelini C, Cea C, Solier A, Pestana D, Muniz-Diaz E, Sandoval E, Paraboschi EM, Navas E, Garcia Sanchez F, Ceriotti F, Martinelli-Boneschi F, Peyvandi F, Blasi F, Tellez L, Blanco-Grau A, Hemmrich-Stanisak G, Grasselli G, Costantino G, Cardamone G, Foti G, Aneli S, Kurihara H, ElAbd H, My I, GalvanFemenia I, Martin J, Erdmann J, Ferrusquia-Acosta J, Garcia-Etxebarria K, Izquierdo-Sanchez L, Bettini LR, Sumoy L, Terranova L, Moreira L, Santoro L, Scudeller L, Mesonero F, Roade L, Ruhlemann MC, Schaefer M, Carrabba M, Riveiro-Barciela M, Figuera Basso ME, Valsecchi MG, Hernandez-Tejero M, AcostaHerrera M, D'Angio M, Baldini M, Cazzaniga M, Schulzky M, Cecconi M, Wittig M, Ciccarelli M, Rodriguez-Gandia M, Bocciolone M, Miozzo M, Montano N, Braun N, Sacchi N, Martinez N, Ozer O, Palmieri O, Faverio P, Preatoni P, Bonfanti P, Omodei P, Tentorio P, Castro P, Rodrigues PM, Blandino Ortiz A, de Cid R, Ferrer R, Gualtierotti R, Nieto R, Goerg S, Badalamenti S, Marsal S, Matullo G, Pelusi S, Juzenas S, Aliberti S, Monzani V, Moreno V, Wesse T, Lenz TL, Pumarola T, Rimoldi 
V, Bosari S, Albrecht W, Peter W, Romero-Gomez M, D'Amato M, Duga S, Banales JM, Hov JR, Folseraas T, Valenti L, Franke A and Karlsen TH. Genomewide Association Study of Severe Covid-19 with Respiratory Failure. $N$ Eng/ J Med. 2020;383:1522-1534.

18. Initiative C-HG. The COVID-19 Host Genetics Initiative, a global initiative to elucidate the role of host genetic factors in susceptibility and severity of the SARSCoV-2 virus pandemic. Eur J Hum Genet. 2020;28:715-718.

19. Burgess S, Scott RA, Timpson NJ, Davey Smith G, Thompson SG and Consortium E-I. Using published data in Mendelian randomization: a blueprint for efficient identification of causal risk factors. Eur J Epidemiol. 2015;30:543-52.

20. Zhang K, Guo Y, Wang Z-X, Ding J-M, Yao S, Chen H, Zhu D-L, Zhang K, Huang W, Dong S-S and Yang T-L. Causally Associations of Blood Lipids Levels with COVID-19 Risk: Mendelian Randomization Study. medRxiv. 2020:2020.07.07.20147926.

21. Kamat MA, Blackshaw JA, Young R, Surendran P, Burgess S, Danesh J, Butterworth AS and Staley JR. PhenoScanner V2: an expanded tool for searching human genotype-phenotype associations. Bioinformatics. 2019;35:4851-4853.

22. Matzaraki V, Kumar V, Wijmenga $C$ and Zhernakova $A$. The MHC locus and genetic susceptibility to autoimmune and infectious diseases. Genome Biol. 2017;18:76.

23. Wellcome Trust Case Control C. Genome-wide association study of 14,000 cases of seven common diseases and 3,000 shared controls. Nature. 2007;447:66178.

24. Tomer Y, Dolan LM, Kahaly G, Divers J, D'Agostino RB, Jr., Imperatore G, Dabelea D, Marcovina S, Black MH, Pihoker C, Hasham A, Hammerstad SS, Greenberg DA, Lotay V, Zhang W, Monti MC, Matheis N and Study SfDiY. Genome wide identification of new genes and pathways in patients with both autoimmune thyroiditis and type 1 diabetes. J Autoimmun. 2015;60:32-9.

25. Zhu Z, Zhang F, Hu H, Bakshi A, Robinson MR, Powell JE, Montgomery GW, Goddard ME, Wray NR, Visscher PM and Yang J. Integration of summary data from GWAS and eQTL studies predicts complex trait gene targets. Nat Genet. 2016;48:481-7.

26. Machiela MJ and Chanock SJ. LDlink: a web-based application for exploring population-specific haplotype structure and linking correlated alleles of possible functional variants. Bioinformatics. 2015;31:3555-3557.

27. Chang CC, Chow CC, Tellier LC, Vattikuti S, Purcell SM and Lee JJ. Second- 
generation PLINK: rising to the challenge of larger and richer datasets. GigaScience. 2015;4:7.

28. Swerdlow DI, Kuchenbaecker KB, Shah S, Sofat R, Holmes MV, White J, Mindell JS, Kivimaki M, Brunner EJ, Whittaker JC, Casas JP and Hingorani AD. Selecting instruments for Mendelian randomization in the wake of genome-wide association studies. Int J Epidemiol. 2016;45:1600-1616.

29. Grover S. Mendelian Randomization: Methods for Using Genetic Variants in Causal Estimation. S.Burgess and S. G.Thompson (2015). London, UK: Chapman \& Hall/CRC Press. 224 pages, ISBN: 9781466573178. Biometrical Journal. 2017;59:1086-1087.

30. Bowden J, Del Greco MF, Minelli C, Davey Smith G, Sheehan N and Thompson J. A framework for the investigation of pleiotropy in two-sample summary data Mendelian randomization. Stat Med. 2017;36:1783-1802.

31. Verbanck M, Chen CY, Neale B and Do R. Detection of widespread horizontal pleiotropy in causal relationships inferred from Mendelian randomization between complex traits and diseases. Nat Genet. 2018;50:693-698.

32. Choi SW and O'Reilly PF. PRSice-2: Polygenic Risk Score software for biobank-scale data. GigaScience. 2019;8.

33. Teuwen LA, Geldhof V, Pasut A and Carmeliet P. COVID-19: the vasculature unleashed. Nat Rev Immunol. 2020;20:389-391.

34. Lin J, Yan H, Chen H, He C, Lin C, He H, Zhang S, Shi S and Lin K. COVID19 and coagulation dysfunction in adults: A systematic review and meta-analysis. Journal of Medical Virology. 2020.

35. Overmyer KA, Shishkova E, Miller IJ, Balnis J, Bernstein MN, Peters-Clarke TM, Meyer JG, Quan Q, Muehlbauer LK, Trujillo EA, He Y, Chopra A, Chieng HC, Tiwari A, Judson MA, Paulson B, Brademan DR, Zhu Y, Serrano LR, Linke V, Drake LA, Adam AP, Schwartz BS, Singer HA, Swanson S, Mosher DF, Stewart R, Coon JJ and Jaitovich A. Large-Scale Multi-omic Analysis of COVID-19 Severity. Cell Syst. 2020.

36. Guan WJ, Ni ZY, Hu Y, Liang WH, Ou CQ, He JX, Liu L, Shan H, Lei CL, Hui DSC, Du B, Li LJ, Zeng G, Yuen KY, Chen RC, Tang CL, Wang T, Chen PY, Xiang J, Li SY, Wang JL, Liang ZJ, Peng YX, Wei L, Liu Y, Hu YH, Peng P, Wang JM, Liu JY, Chen Z, Li G, Zheng ZJ, Qiu SQ, Luo J, Ye CJ, Zhu SY, Zhong NS and China Medical Treatment Expert Group for C. Clinical Characteristics of Coronavirus Disease 2019 in China. N Engl J Med. 2020;382:1708-1720.

37. Gao F, Zheng KNI, Wang XB, Sun QF, Pan KH, Wang TY, Chen YP, Targher 
G, Byrne CD, George J and Zheng MH. Obesity Is a Risk Factor for Greater COVID19 Severity. Diabetes Care. 2020;43:E72-E74.

38. Belanger MJ, Hill MA, Angelidi AM, Dalamaga M, Sowers JR and Mantzoros CS. Covid-19 and Disparities in Nutrition and Obesity. N Engl J Med. 2020;383:e69.

39. Holman N, Knighton P, Kar P, O'Keefe J, Curley M, Weaver A, Barron E, Bakhai C, Khunti K, Wareham NJ, Sattar N, Young B and Valabhji J. Risk factors for COVID-19-related mortality in people with type 1 and type 2 diabetes in England: a population-based cohort study. Lancet Diabetes Endocrinol. 2020;8:823-833.

40. Sin DD. COVID-19 in COPD: A growing concern. EClinicalMedicine. 2020;26:100546.

41. Cummings MJ, Baldwin MR, Abrams D, Jacobson SD, Meyer BJ, Balough EM, Aaron JG, Claassen J, Rabbani LE, Hastie J, Hochman BR, Salazar-Schicchi J, Yip NH, Brodie D and O'Donnell MR. Epidemiology, clinical course, and outcomes of critically ill adults with COVID-19 in New York City: a prospective cohort study. Lancet. 2020;395:1763-1770.

42. Petrilli CM, Jones SA, Yang J, Rajagopalan H, O'Donnell L, Chernyak Y, Tobin KA, Cerfolio RJ, Francois F and Horwitz LI. Factors associated with hospital admission and critical illness among 5279 people with coronavirus disease 2019 in New York City: prospective cohort study. BMJ. 2020;369:m1966.

43. Williamson EJ, Walker AJ, Bhaskaran K, Bacon S, Bates C, Morton CE, Curtis HJ, Mehrkar A, Evans D, Inglesby P, Cockburn J, McDonald HI, MacKenna B, Tomlinson L, Douglas IJ, Rentsch CT, Mathur R, Wong AYS, Grieve R, Harrison D, Forbes H, Schultze A, Croker R, Parry J, Hester F, Harper S, Perera R, Evans SJW, Smeeth $L$ and Goldacre B. Factors associated with COVID-19-related death using OpenSAFELY. Nature. 2020;584:430-436.

44. Middeldorp S, Coppens M, van Haaps TF, Foppen M, Vlaar AP, Muller MCA, Bouman CCS, Beenen LFM, Kootte RS, Heijmans J, Smits LP, Bonta PI and van Es $\mathrm{N}$. Incidence of venous thromboembolism in hospitalized patients with COVID-19. $J$ Thromb Haemost. 2020;18:1995-2002.

45. Poissy J, Goutay J, Caplan M, Parmentier E, Duburcq T, Lassalle F, Jeanpierre E, Rauch A, Labreuche J, Susen S and Lille ICUHC-G. Pulmonary Embolism in Patients With COVID-19: Awareness of an Increased Prevalence. Circulation. 2020;142:184-186.

46. Zhang L, Feng X, Zhang D, Jiang C, Mei H, Wang J, Zhang C, Li H, Xia X, Kong S, Liao J, Jia H, Pang X, Song Y, Tian Y, Wang B, Wu C, Yuan H, Zhang Y, Li Y, Sun W, Zhang Y, Zhu S, Wang S, Xie Y, Ge S, Zhang L, Hu Y and Xie M. Deep 
Vein Thrombosis in Hospitalized Patients With COVID-19 in Wuhan, China. Circulation. 2020;142:114-128.

47. Bilaloglu S, Aphinyanaphongs $\mathrm{Y}$, Jones S, Iturrate E, Hochman J and Berger JS. Thrombosis in Hospitalized Patients With COVID-19 in a New York City Health System. JAMA. 2020;324:799-801.

48. Desch KC. Regulation of plasma von Willebrand factor. F1000Res. 2018;7:96. 49. Bryckaert M, Rosa JP, Denis CV and Lenting PJ. Of von Willebrand factor and platelets. Cell Mol Life Sci. 2015;72:307-26.

50. Dong JF, Moake JL, Nolasco L, Bernardo A, Arceneaux W, Shrimpton CN, Schade AJ, Mclntire LV, Fujikawa K and Lopez JA. ADAMTS-13 rapidly cleaves newly secreted ultralarge von Willebrand factor multimers on the endothelial surface under flowing conditions. Blood. 2002;100:4033-9.

51. Koster T, Blann AD, Briet E, Vandenbroucke JP and Rosendaal FR. Role of clotting factor VIII in effect of von Willebrand factor on occurrence of deep-vein thrombosis. Lancet. 1995;345:152-5.

52. Sadler JE. Von Willebrand factor, ADAMTS13, and thrombotic thrombocytopenic purpura. Blood. 2008;112:11-8.

53. Obermeier HL, Riedl J, Ay C, Koder S, Quehenberger P, Bartsch R, Kaider A, Zielinski CC and Pabinger I. The role of ADAMTS-13 and von Willebrand factor in cancer patients: Results from the Vienna Cancer and Thrombosis Study. Res Pract Thromb Haemost. 2019;3:503-514.

54. Pepin M, Kleinjan A, Hajage D, Buller HR, Di Nisio M, Kamphuisen PW, Salomon L, Veyradier A, Stepanian A and Mahe I. ADAMTS-13 and von Willebrand factor predict venous thromboembolism in patients with cancer. J Thromb Haemost. 2016;14:306-15.

55. Matsukawa M, Kaikita K, Soejima K, Fuchigami S, Nakamura Y, Honda T, Tsujita K, Nagayoshi Y, Kojima S, Shimomura H, Sugiyama S, Fujimoto K, Yoshimura M, Nakagaki $T$ and Ogawa $H$. Serial changes in von Willebrand factorcleaving protease (ADAMTS13) and prognosis after acute myocardial infarction. $\mathrm{Am}$ J Cardiol. 2007;100:758-63.

56. Zhao J, Yang Y, Huang H, Li D, Gu D, Lu X, Zhang Z, Liu L, Liu T, Liu Y, He Y, Sun B, Wei M, Yang G, Wang X, Zhang L, Zhou X, Xing $M$ and Wang PG. Relationship between the ABO Blood Group and the COVID-19 Susceptibility. Clin Infect Dis. 2020.

57. Zeng X, Fan H, Lu D, Huang F, Meng X, Li Z, Tang M, Zhang J, Liu N, Liu Z, Zhao J, Yin W, An Q, Zhang $X$ and $\mathrm{Hu} X$. Association between $A B O$ blood groups 
and clinical outcome of coronavirus disease 2019: Evidence from two cohorts. medRxiv. 2020:2020.04.15.20063107.

58. Rao S, Lau A and So HC. Exploring Diseases/Traits and Blood Proteins Causally Related to Expression of ACE2, the Putative Receptor of SARS-CoV-2: A Mendelian Randomization Analysis Highlights Tentative Relevance of DiabetesRelated Traits. Diabetes Care. 2020;43:1416-1426.

59. Latz CA, DeCarlo C, Boitano L, Png CYM, Patell R, Conrad MF, Eagleton M and Dua A. Blood type and outcomes in patients with COVID-19. Ann Hematol. 2020;99:2113-2118.

60. Chung CM, Wang RY, Chen JW, Fann CSJ, Leu HB, Ho HY, Ting CT, Lin TH, Sheu SH, Tsai WC, Chen JH, Jong YS, Lin SJ, Chen YT and Pan WH. A genomewide association study identifies new loci for ACE activity: potential implications for response to ACE inhibitor. The Pharmacogenomics Journal. 2010;10:537-544.

61. Hernandez Cordero Al, Li X, Milne S, Yang CX, Bosse Y, Joubert P, Timens W, Berge Mvd, Nickle D, Hao K and Sin DD. Multi-omics highlights ABO plasma protein as a causal risk factor for COVID-19. 2020:2020.10.05.20207118.

62. Sabater-Lleal M, Huffman JE, de Vries PS, Marten J, Mastrangelo MA, Song C, Pankratz N, Ward-Caviness CK, Yanek LR, Trompet S, Delgado GE, Guo X, Bartz TM, Martinez-Perez A, Germain M, de Haan HG, Ozel AB, Polasek O, Smith AV, Eicher JD, Reiner AP, Tang W, Davies NM, Stott DJ, Rotter JI, Tofler GH, Boerwinkle E, de Maat MPM, Kleber ME, Welsh P, Brody JA, Chen MH, Vaidya D, Soria JM, Suchon P, van Hylckama Vlieg A, Desch KC, Kolcic I, Joshi PK, Launer LJ, Harris TB, Campbell H, Rudan I, Becker DM, Li JZ, Rivadeneira F, Uitterlinden AG, Hofman A, Franco $\mathrm{OH}$, Cushman $\mathrm{M}$, Psaty BM, Morange PE, McKnight $\mathrm{B}$, Chong MR, Fernandez-Cadenas I, Rosand J, Lindgren A, Consortium I, Consortium MCotISG, Gudnason V, Wilson JF, Hayward C, Ginsburg D, Fornage M, Rosendaal FR, Souto JC, Becker LC, Jenny NS, Marz W, Jukema JW, Dehghan A, Tregouet DA, Morrison $A C$, Johnson AD, O'Donnell CJ, Strachan DP, Lowenstein CJ and Smith NL. Genome-Wide Association Transethnic Meta-Analyses Identifies Novel Associations Regulating Coagulation Factor VIII and von Willebrand Factor Plasma Levels. Circulation. 2019;139:620-635.

63. Franchini M, Capra F, Targher G, Montagnana M and Lippi G. Relationship between $\mathrm{ABO}$ blood group and von Willebrand factor levels: from biology to clinical implications. Thromb J. 2007;5:14.

64. Jenkins PV and O'Donnell JS. ABO blood group determines plasma von Willebrand factor levels: a biologic function after all? Transfusion. 2006;46:1836-44. 
65. Elliott J, Bodinier B, Bond TA, Chadeau-Hyam M, Evangelou E, Moons KGM, Dehghan A, Muller DC, Elliott P and Tzoulaki I. Predictive Accuracy of a Polygenic Risk Score-Enhanced Prediction Model vs a Clinical Risk Score for Coronary Artery Disease. JAMA. 2020;323:636-645.

66. Abraham G, Malik R, Yonova-Doing E, Salim A, Wang T, Danesh J, Butterworth AS, Howson JMM, Inouye M and Dichgans M. Genomic risk score offers predictive performance comparable to clinical risk factors for ischaemic stroke. Nature Communications. 2019;10:5819.

67. Miller $\mathrm{CH}$, Dilley A, Richardson L, Hooper WC and Evatt BL. Population differences in von Willebrand factor levels affect the diagnosis of von Willebrand disease in African-American women. Am J Hematol. 2001;67:125-9.

68. Sukhu K, Poovalingam V, Mahomed R and Giangrande PL. Ethnic variation in von Willebrand factor levels can influence the diagnosis of von Willebrand disease. Clin Lab Haematol. 2003;25:247-9.

69. Helms J, Tacquard C, Severac F, Leonard-Lorant I, Ohana M, Delabranche X, Merdji H, Clere-Jehl R, Schenck M, Fagot Gandet F, Fafi-Kremer S, Castelain V, Schneider F, Grunebaum L, Angles-Cano E, Sattler L, Mertes PM, Meziani F and Group CT. High risk of thrombosis in patients with severe SARS-CoV-2 infection: a multicenter prospective cohort study. Intensive Care Med. 2020;46:1089-1098.

70. Panigada M, Bottino N, Tagliabue P, Grasselli G, Novembrino C, Chantarangkul V, Pesenti A, Peyvandi F and Tripodi A. Hypercoagulability of COVID19 patients in intensive care unit: $A$ report of thromboelastography findings and other parameters of hemostasis. J Thromb Haemost. 2020;18:1738-1742.

71. Bazzan M, Montaruli B, Sciascia S, Cosseddu D, Norbiato C and Roccatello D. Low ADAMTS 13 plasma levels are predictors of mortality in COVID-19 patients. Intern Emerg Med. 2020;15:861-863.

72. Krishnamachary B, Cook C, Spikes L, Chalise $P$ and Dhillon NK. The Potential Role of Extracellular Vesicles in COVID-19 Associated Endothelial injury and Pro-inflammation. medRxiv. 2020:2020.08.27.20182808.

73. Adam $\mathrm{EH}$, Zacharowski $\mathrm{K}$ and Miesbach W. A comprehensive assessment of the coagulation profile in critically ill COVID-19 patients. Thromb Res. 2020;194:4244.

74. Doevelaar AAN, Bachmann M, Hoelzer B, Seibert FS, Rohn BS, Bauer F, Witzke O, Dittmer U, Bachmann M, Yilmaz S, Dittmer R, Schneppenheim S, Babel N, Budde $U$ and Westhoff TH. COVID-19 is associated with relative ADAMTS13 deficiency and VWF multimer formation resembling TTP. medRxiv. 
medRxiv preprint doi: https://doi.org/10.1101/2020.11.20.20235440; this version posted December 3, 2020. The copyright holder for this preprint (which was not certified by peer review) is the author/funder, who has granted medRxiv a license to display the preprint in perpetuity.

\author{
It is made available under a CC-BY-NC-ND 4.0 International license.
}

2020:2020.08.23.20177824. 
Tables

Table 1. Summary statistics of the MR estimates of coagulation factors on COVID-19 severity

\begin{tabular}{|c|c|c|c|c|c|c|c|c|c|c|c|c|c|c|}
\hline Exposure & nSNPs & $\begin{array}{l}\text { IVW OR } \\
(95 \% \text { CI })\end{array}$ & $P_{\mathrm{IVW}}$ & $\begin{array}{c}\text { Egger OR } \\
(95 \% \text { CI })\end{array}$ & $P_{\text {Egger }}$ & $\begin{array}{c}\text { WM OR } \\
(95 \% \text { CI })\end{array}$ & $P_{\mathrm{WM}}$ & $\begin{array}{l}\text { IVW OR } \\
(95 \% \text { CI) }\end{array}$ & $P_{\text {IVW }}$ & $\begin{array}{c}\text { Egger OR } \\
(95 \% \text { CI })\end{array}$ & $P_{\text {Egger }}$ & $\begin{array}{l}\text { WM OR } \\
(95 \% \text { CI })\end{array}$ & $P_{\mathrm{WM}}$ & 家寅 \\
\hline & & \multicolumn{6}{|c|}{ The Severe COVID-19 GWAS Group ${ }^{17}$} & \multicolumn{6}{|c|}{ The COVID-19 Host Genetics Initiative ${ }^{18}$} & $\overline{\bar{\omega}} \overline{\bar{\phi}}$ \\
\hline VWF & 17 & $\begin{array}{c}1.35 \\
(1.09-1.68)\end{array}$ & 0.005 & $\begin{array}{c}1.62 \\
(1.24-2.13)\end{array}$ & 0.003 & $\begin{array}{c}1.47 \\
(1.09-2.00)\end{array}$ & 0.012 & $\begin{array}{c}1.15 \\
(0.99-1.34)\end{array}$ & 0.060 & $\begin{array}{c}1.18 \\
(0.98-1.43)\end{array}$ & 0.105 & $\begin{array}{c}1.21 \\
(1.01-1.46)\end{array}$ & $\mathbf{0 . 0 3 9}$ & \\
\hline ADAMTS13 & 4 & $\begin{array}{c}0.69 \\
(0.50-0.96)\end{array}$ & 0.025 & $\begin{array}{c}0.62 \\
(0.25-1.53)\end{array}$ & 0.409 & $\begin{array}{c}0.69 \\
(0.48-0.99)\end{array}$ & 0.044 & $\begin{array}{c}1.00 \\
(0.77-1.29)\end{array}$ & 0.983 & $\begin{array}{c}1.18 \\
(0.58-2.38)\end{array}$ & 0.697 & $\begin{array}{c}1.00 \\
(0.75-1.32)\end{array}$ & 0.976 & 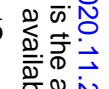 \\
\hline D-dimer & 3 & $\begin{array}{c}3.80 \\
(0.52-27.90)\end{array}$ & 0.189 & $\begin{array}{c}133.44 \\
(0.01- \\
2203234.91)\end{array}$ & 0.504 & $\begin{array}{c}3.66 \\
(0.28-47.28)\end{array}$ & 0.320 & $\begin{array}{c}0.61 \\
(0.19-2.01)\end{array}$ & 0.421 & $\begin{array}{c}32.23 \\
(0.22-4646.69)\end{array}$ & 0.402 & $\begin{array}{c}0.94 \\
(0.26-3.43)\end{array}$ & 0.925 & 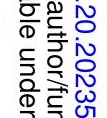 \\
\hline PAI-1 & 5 & $\begin{array}{c}0.82 \\
(0.31-2.14)\end{array}$ & 0.685 & $\begin{array}{c}0.06 \\
(0.01-9.19)\end{array}$ & 0.348 & $\begin{array}{c}0.58 \\
(0.17-1.92)\end{array}$ & 0.371 & $\begin{array}{c}1.18 \\
(0.73-1.91)\end{array}$ & 0.504 & $\begin{array}{c}1.67 \\
(0.12-22.93)\end{array}$ & 0.726 & $\begin{array}{c}1.25 \\
(0.72-2.17)\end{array}$ & 0.433 & مి \\
\hline $\mathrm{tPA}$ & 3 & $\begin{array}{c}1.46 \\
(0.15-14.27)\end{array}$ & 0.743 & $\begin{array}{c}1.51 \\
(0.01-752.29)\end{array}$ & 0.918 & $\begin{array}{c}0.88 \\
(0.14-5.75)\end{array}$ & 0.897 & $\begin{array}{c}1.42 \\
(0.65-3.08)\end{array}$ & 0.376 & $\begin{array}{c}2.46 \\
(0.01-618.55)\end{array}$ & 0.803 & $\begin{array}{c}1.71 \\
(0.75-3.89)\end{array}$ & 0.204 & 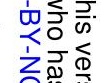 \\
\hline FVII & 8 & $\begin{array}{c}1.07 \\
(0.85-1.35)\end{array}$ & 0.569 & $\begin{array}{c}0.95 \\
(0.70-1.28)\end{array}$ & 0.742 & $\begin{array}{c}1.04 \\
(0.81-1.34)\end{array}$ & 0.769 & $\begin{array}{c}1.01 \\
(0.86-1.20)\end{array}$ & 0.892 & $\begin{array}{c}0.96 \\
(0.77-1.21)\end{array}$ & 0.767 & $\begin{array}{c}0.99 \\
(0.87-1.14)\end{array}$ & 0.921 & 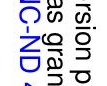 \\
\hline PT & 6 & $\begin{array}{c}1.26 \\
(0.82-1.94)\end{array}$ & 0.294 & $\begin{array}{c}1.04 \\
(0.51-2.11)\end{array}$ & 0.917 & $\begin{array}{c}1.13 \\
(0.69-1.83)\end{array}$ & 0.631 & $\begin{array}{c}0.74 \\
(0.54-1.02)\end{array}$ & 0.062 & $\begin{array}{c}0.65 \\
(0.39-1.09)\end{array}$ & 0.177 & $\begin{array}{c}0.73 \\
(0.50-1.06)\end{array}$ & 0.097 & 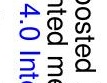 \\
\hline FXI & 3 & $\begin{array}{c}1.01 \\
(0.79-1.29)\end{array}$ & 0.934 & $\begin{array}{c}0.96 \\
(0.59-1.58)\end{array}$ & 0.904 & $\begin{array}{c}1.01 \\
(0.78-1.29)\end{array}$ & 0.958 & $\begin{array}{c}1.03 \\
(0.89-1.18)\end{array}$ & 0.711 & $\begin{array}{c}0.95 \\
(0.66-1.35)\end{array}$ & 0.811 & $\begin{array}{c}1.02 \\
(0.89-1.18)\end{array}$ & 0.745 & 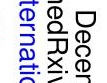 \\
\hline aPTT & 6 & $\begin{array}{c}0.81 \\
(0.59-1.13)\end{array}$ & 0.223 & $\begin{array}{c}1.08 \\
(0.52-2.23)\end{array}$ & 0.849 & $\begin{array}{c}0.98 \\
(0.80-1.20)\end{array}$ & 0.839 & $\begin{array}{c}1.00 \\
(0.90-1.10)\end{array}$ & 0.921 & $\begin{array}{c}0.89 \\
(0.73-1.09)\end{array}$ & 0.315 & $\begin{array}{c}0.98 \\
(0.88-1.10)\end{array}$ & 0.751 & 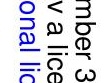 \\
\hline FVIII & 11 & $\begin{array}{c}0.69 \\
(0.36-1.32)\end{array}$ & 0.262 & $\begin{array}{c}0.68 \\
(0.03-17.22)\end{array}$ & 0.819 & $\begin{array}{c}0.95 \\
(0.41-2.22)\end{array}$ & 0.913 & $\begin{array}{c}1.35 \\
(0.88-2.08)\end{array}$ & 0.172 & $\begin{array}{c}2.71 \\
(0.41-18.13)\end{array}$ & 0.331 & $\begin{array}{c}1.17 \\
(0.65-2.09)\end{array}$ & 0.601 & 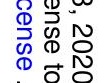 \\
\hline FX & 3 & $\begin{array}{c}0.98 \\
(0.74-1.31)\end{array}$ & 0.908 & $\begin{array}{c}1.57 \\
(0.70-3.50)\end{array}$ & 0.472 & $\begin{array}{c}0.93 \\
(0.67-1.30)\end{array}$ & 0.676 & $\begin{array}{c}0.83 \\
(0.65-1.07)\end{array}$ & 0.152 & $\begin{array}{c}0.82 \\
(0.40-1.72)\end{array}$ & 0.697 & $\begin{array}{c}0.84 \\
(0.64-1.10)\end{array}$ & 0.199 & \\
\hline ETP & 3 & $\begin{array}{c}1.06 \\
(0.74-1.51)\end{array}$ & 0.761 & $\begin{array}{c}1.05 \\
(0.40-2.75)\end{array}$ & 0.937 & $\begin{array}{c}0.98 \\
(0.73-1.31)\end{array}$ & 0.881 & $\begin{array}{c}1.06 \\
(0.90-1.25)\end{array}$ & 0.503 & $\begin{array}{c}1.04 \\
(0.76-1.42)\end{array}$ & 0.851 & $\begin{array}{c}1.05 \\
(0.88-1.25)\end{array}$ & 0.580 & \\
\hline
\end{tabular}


Values in bold indicate statistically significant results.

Abbreviations: VWF, von Willebrand factor; ADAMTS13, a disintegrin and metalloproteinase with a thrombospondin type 1 motif, member 13; tPA, tissue plasminogen activator; PAI-1, plasminogen activator inhibitor-1; FVII, Factor VII; PT, prothrombin time; FVIII, Factor VIII; FXI, Factor XI; aPTT, activated partial thromboplastin time; FX, Factor X; ETP, endogenous thrombin potential. 
Table 2. Supporting evidence for the associations between VWF/ADAMTS13 activities and COVID-19 severity

\begin{tabular}{|c|c|c|c|c|c|}
\hline Study & PMID & Area & $\begin{array}{l}\text { Sample } \\
\text { size }\end{array}$ & Criteria for severity & Findings \\
\hline Helms J ${ }^{69}$ & 32367170 & French & 150 & Admitted to ICU & $\begin{array}{l}\text { VWF antigen level was increased in } \\
\text { patients with severe COVID-19 } \\
\text { compared to healthy controls }\end{array}$ \\
\hline Panigada $\mathrm{M}^{70}$ & 32302438 & Italy & 24 & $\begin{array}{l}\text { Admitted to ICU because of } \\
\text { acute respiratory syndromes }\end{array}$ & $\begin{array}{l}\text { VWF antigen level was } \\
\text { considerably increased in ICU } \\
\text { patients compared to healthy } \\
\text { controls }\end{array}$ \\
\hline Bazzan $\mathbf{M}^{71}$ & 32557383 & $\begin{array}{l}\text { United } \\
\text { States }\end{array}$ & 88 & Death & $\begin{array}{l}\text { Patients who died had significant } \\
\text { lower levels of ADAMTS13 and } \\
\text { higher levels of VWF compared to } \\
\text { patients with non-fatal outcome }\end{array}$ \\
\hline $\begin{array}{l}\text { Krishnamachary } \\
\mathrm{B}^{72}\end{array}$ & 32909001 & $\begin{array}{l}\text { United } \\
\text { States }\end{array}$ & 53 & $\begin{array}{l}\text { Requires oxygen delivery by } \\
\text { non-rebreather mask, non- } \\
\text { invasive ventilation, or heated } \\
\text { high flow nasal cannula at a } \\
\text { minimum }\end{array}$ & $\begin{array}{l}\text { Significantly elevated levels of } \\
\text { VWF and decreased ADAMTS13 in } \\
\text { large extracellular vesicles from } \\
\text { patients with severe COVID-19 } \\
\text { compared to healthy controls }\end{array}$ \\
\hline Overmyer KA ${ }^{35}$ & 32743614 & $\begin{array}{l}\text { United } \\
\text { States }\end{array}$ & 128 & Admitted to ICU & $\begin{array}{l}\text { VWF level was increased in ICU } \\
\text { patients versus in non-ICU patients }\end{array}$ \\
\hline Adam $\mathrm{EH}^{73}$ & 32723615 & Germany & 4 & Admitted to ICU & $\begin{array}{l}\text { Elevated levels of VWF and } \\
\text { decreased ADAMTS13 in ICU } \\
\text { patients }\end{array}$ \\
\hline Adrian $\mathrm{AN}^{74}$ & medRxiv & Germany & 85 & $\begin{array}{l}\text { The severity degree of COVID- } \\
19 \text { was categorized according to } \\
\text { the guidelines of the Robert } \\
\text { Koch Institute, Germany }\end{array}$ & $\begin{array}{l}\text { Elevated levels of VWF and } \\
\text { decreased ADAMTS13/VWF ratio } \\
\text { in severe patients }\end{array}$ \\
\hline Goshua, $\mathrm{G}^{9}$ & 32619411 & $\begin{array}{l}\text { United } \\
\text { States }\end{array}$ & 68 & Admitted to ICU & $\begin{array}{l}\text { VWF antigen level was significantly } \\
\text { elevated in ICU patients compared } \\
\text { with non-ICU patients }\end{array}$ \\
\hline
\end{tabular}

Abbreviations:

ICU, intensive care unit; VWF, von Willebrand factor; ADAMTS13, a disintegrin and metalloproteinase with a thrombospondin type 1 motif, member 13 


\section{Figure legends}

Figure 1. Forest plot of the associations of genetically determined coagulation factors and COVID-19 severity.

Forest plot shows odds ratio (OR) and 95\% confidence interval (CI) from the results of IVW MR. The solid lines indicate MR results based on COVID-19 GWAS data from the Severe COVID-19 GWAS Group ${ }^{17}$ and the dashed lines indicate MR results based on COVID-19 GWAS data from COVID-19 Host Genetics Initiative ${ }^{18}$. D-dimer and tPA are excluded in this plot for abnormal OR values.

Figure 2. Predictive ability of VWF PRS and clinical risk factors against COVID-19 severity.

(A) Receiver operating characteristic (ROC) for logistic regression using clinical risk factors and PRS derived from VWF GWAS as independent variables, area under the receiver operating characteristic curve (AUC) was the mean value for 10-fold cross validation. (B) Barplot depicts the normalized effect size of each contributing variable, values of each bar are coefficients of logistic regression after normalizing raw values to the same scale via z-score normalization. Abbreviations: BMI, body mass index; CAD, coronary artery disease; COPD, chronic obstructive pulmonary disease; PRS, polygenic risk score; T2DM, type 2 diabetes mellitus; 
A

Receiver operating characteristic

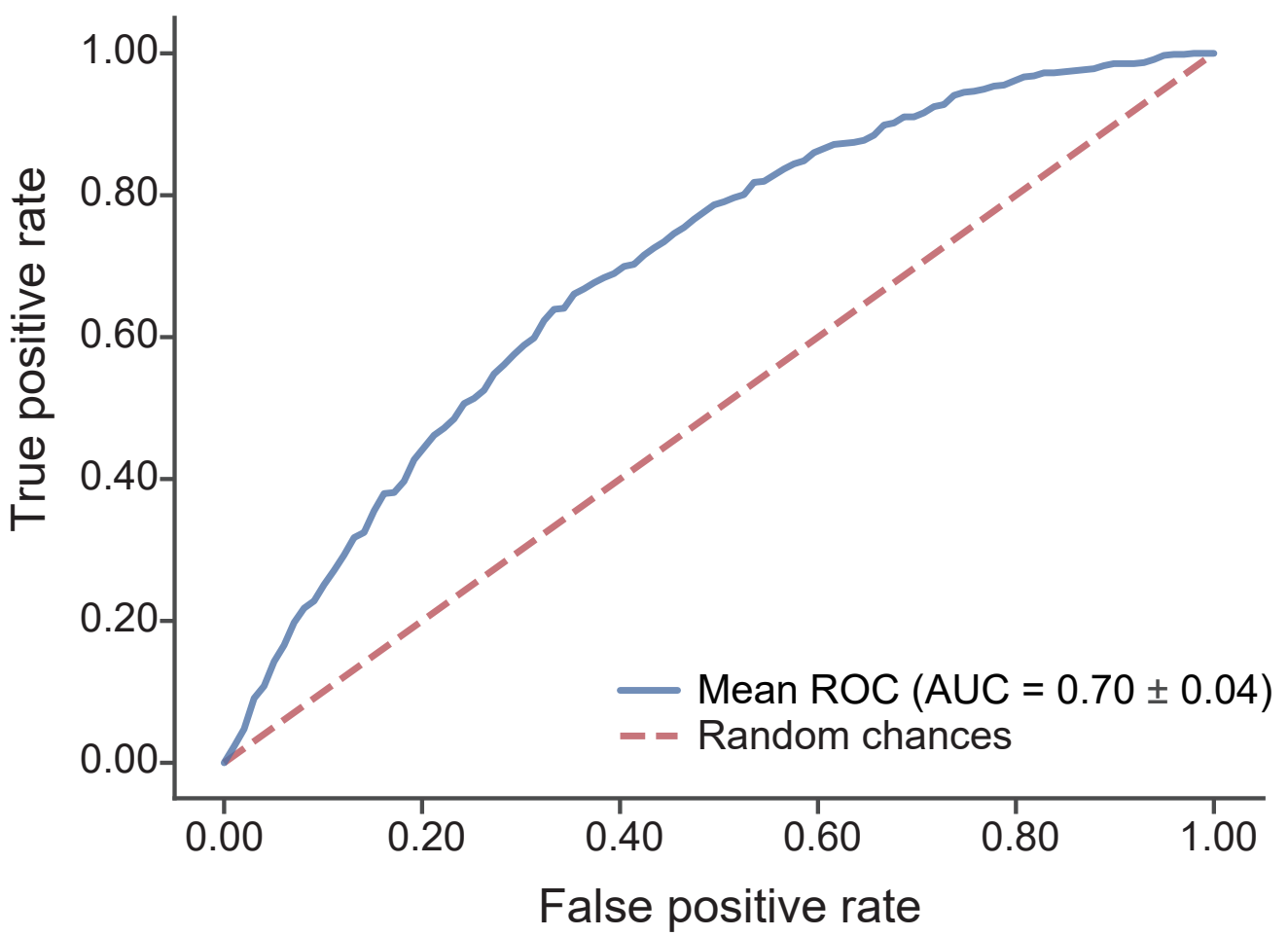

B

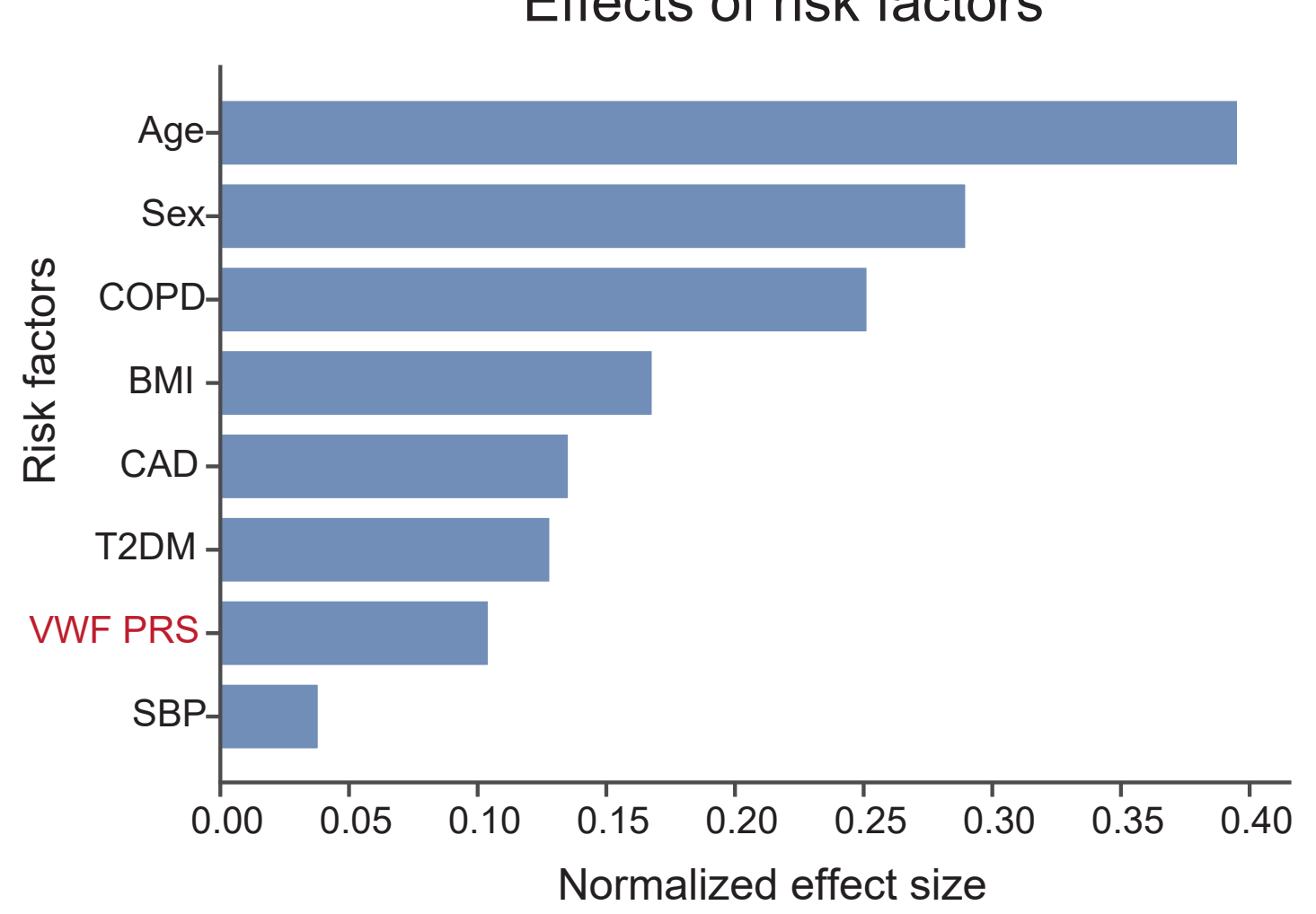

